\title{
Polyurethane foams with pyrimidine rings
}

\author{
Ewelina Kania, Jacek Lubczak* \\ Rzeszów University of Technology, Department of Organic Chemistry, al. Powstańców Warszawy 6, 35-959 Rzeszów, Poland \\ *Corresponding author: e-mail: jml@prz.rzeszow.pl
}

\begin{abstract}
Oligoetherols based on pyrimidine ring were obtained upon reaction of barbituric acid with glycidol and alkylene carbonates. These oligoetherols were then used to obtain polyurethane foams in the reaction of oligoetherols with isocyanates and water. The protocol of foam synthesis was optimized by the choice of proper kind of oligoetherol and synthetic composition. The thermal resistance was studied by dynamic and static methods with concomitant monitoring of compressive strength. The polyurethane foams have similar physical properties as the classic ones except their enhanced thermal resistance. They stand long-time heating even at $200^{\circ} \mathrm{C}$. Moreover thermal exposition of foams results generally in increase of their compressive strength.
\end{abstract}

Keywords: barbituric acid, glycidol, alkylene carbonates, oligoetherols, polyurethane foams, thermal stability.

\section{INTRODUCTION}

Introduction of azacyclic, most often perhydro-1,3,5-triazine ${ }^{1,2}, 1,3,5$-triazine ${ }^{3}$, purine or $^{4}$ carbazole ${ }^{5-7}$ rings into the structure of polyurethane (PU) generally results in obtaining rigid polyurethane foams of enhanced thermal stability. The suitable protocol involves the synthesis of oligoetherols in straightforward reaction of azacycles with oxiranes or alkylene carbonates in primary step ${ }^{8}$. Then, the oligoetherols are subjected to the reaction with multifunctional isocyanates and water to get PU foams. This method is not effective when barbituric acid (BA) is used as substrate for oligoetherols due to conversion of BA into its trienol form upon heating in ethylene or propylene oxide (EO and PO, respectively) or in ethylene or propylene carbonates (EC and PC, respectively $)^{9}$. This phenomenon can be omitted, when BA is converted to oligoetherols by reaction with glycidol and further with oxiranes or alkylene carbonates, as shown at following scheme ${ }^{\mathbf{1 0}}$ :
The final oligoetherols (I) can be used for formation of PU foams of enhanced thermal resistance related to presence of pyrimidine ring. This was demonstrated recently for 1,3-dihydroxyalkyl 5,5-diethylbarbiturates used as substrates for formation of polyacrylates and polymethacrylates ${ }^{\mathbf{1 1}}$, as well as linear polyurethanes of enhanced thermal resistance ${ }^{12}$.

The oligoetherols with pyrimidine ring could be obtained from tetrafunctional derivatives of BA with excess of oxiranes as shown at the scheme below ${ }^{13}$.

The oligoetherols obtained in that way were suitable substrates to form PU foams of enhanced thermal resistance. The disadvantage of hydroxymethyl derivatives of BA was their migration of formaldehyde from $\mathrm{N}$ -oxymethylene groups according to following scheme 3 .

The method of obtaining oligoetherols with pyrimidine ring (II) was also reported ${ }^{14}$. They were also useful to form polyurethane foams of enhanced thermal resistance<smiles>CN1C(=O)NC(=O)C(CN2C(=O)N(CC(O)CO)C(=O)C(C)(CC(O)CO)C2=O)C1=O</smiles>

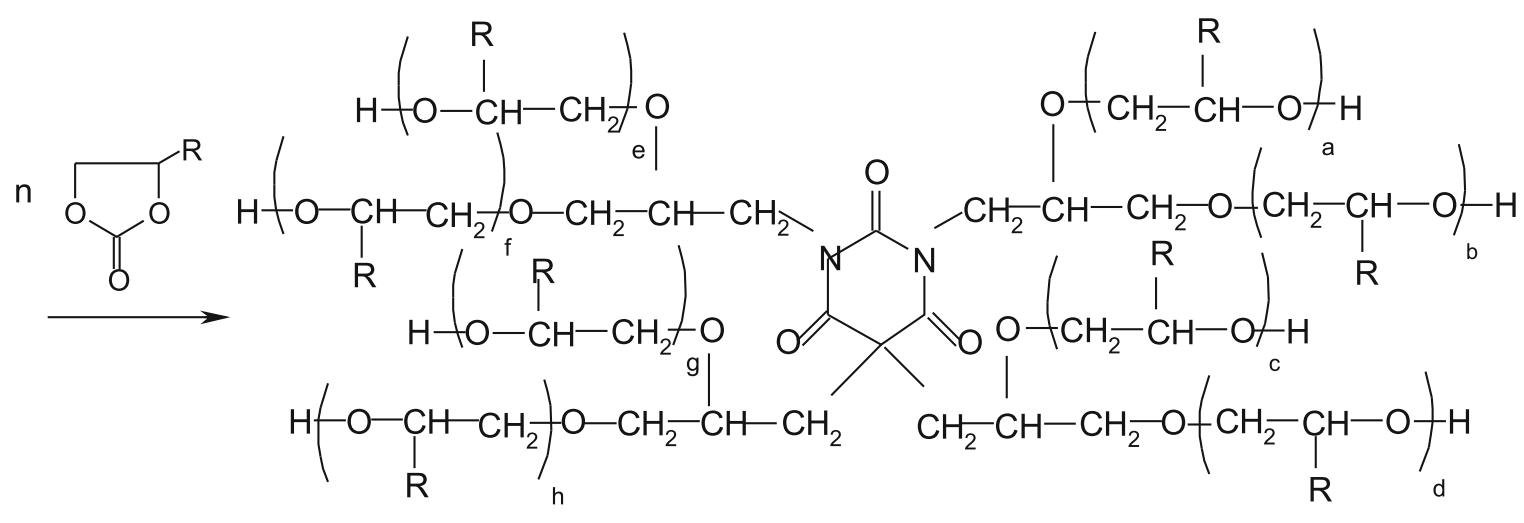

where: $a+b+c+d+e+f+g+h=n$

Scheme 1. Reaction of barbituric acid with glycidol 


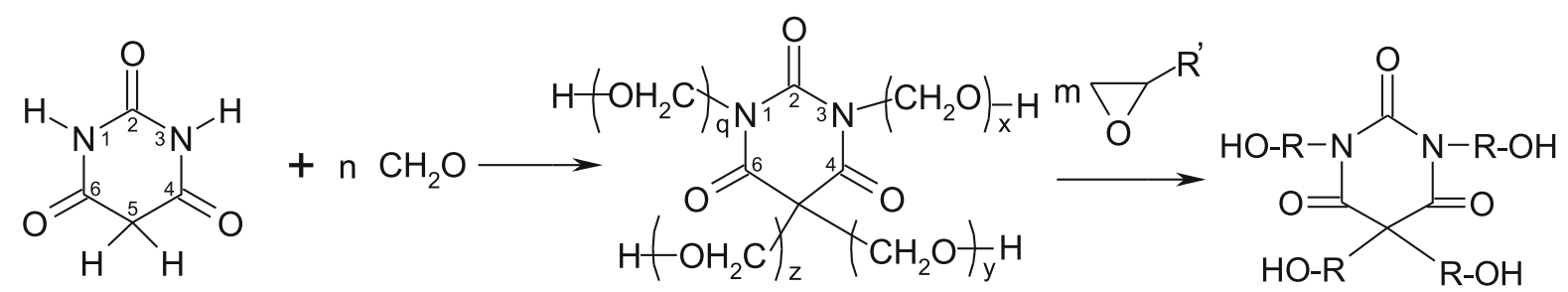

where: $x+y+z+q=n$ and $R^{\prime}+-H,-C_{3}$ and $R$ - oxyalkylene groups

Scheme 2. Synthesis of oligoetherols by reaction of BA with formaldehyde and oxiranes<smiles></smiles>

Scheme 3. Formaldehyde release from semiproduct

by reaction of 6-aminouracil (AU) with excess of oxiranes in $\mathrm{DMSO}^{15}$ :<smiles>[R]C(O)Cn1c(N([Y2])CC([R])O[Hg])cc(=O)n(CC([R])O[TlH])c1=O</smiles>

where $\mathrm{x}+\mathrm{y}+\mathrm{z}-$ number of oxirane equivalents attached to 6 -aminouracil $\mathrm{R}=\mathrm{H}-, \mathrm{CH}_{3}-$

Scheme 4. General formula of oligoetherol obtained from 6-aminouracil and oxiranes

6-Aminouracil does not dissolve well in organic solvents except DMSO, which must be removed after synthesis. The products of decomposition of DMSO in high temperature treatment of the product are still present in oligoetherols. Another disadvantage is the use of low boiling, toxic, and flammable and potentially explosive (with air) oxiranes, which renders processing hazardous ${ }^{\mathbf{1 6}}$.

This paper describes the results of obtaining thermally resistant PU foams with pyrimidine ring. The oligoetherols obtained from BA, glycidol and alkylene carbonates: $\mathrm{EC}$ and PC were starting materials. The straightforward sequential reactions of BA with glycidol and with alkylene carbonates allowed to obtain oligoetherols of higher functionality than those obtained previously from BA with formaldehyde and further with oxiranes. The obtained multifunctional oligoetherols appeared to be

Table 1. Conditions of hydroxyalkylation of BA better starting materials for polyurethanes with high crosslinking degree to give rigid and mechanically stable polyurethane foams.

\section{EXPERIMENTAL SECTION}

\section{Syntheses}

Syntheses of oligoetherols with pyrimidine ring were conducted according to protocol descri-bed in $^{\mathbf{1 0}}$. Initial molar ratio of reagents and reaction conditions are presented in Table 1.

\section{Analytical methods}

The progress of reaction was monitored as described in $^{10}$, namely the reaction between BA and GL or alkylene oxides was followed by measuring the content of unreacted epoxide groups by hydrochloric acid method in dioxane ${ }^{17}$. The progress of reaction with alkylene carbonates was monitored by determination of unreacted alkylene carbonate with barium hydroxide as described in ${ }^{18}$. The products were also controlled by mass balance, elemental analysis, hydroxyl (HN) and acidic numbers ${ }^{19}$ (AN) of oligoetherols. The following physical properties were determined: density, viscosity, and surface tension of oligoetherols were determined with picnometer, Höppler viscosimeter (type BHZ, prod. Prüfgeratewerk, Germany) and by the detaching ring method, respectively. The oligoetherols were dried over molecular sieves A4 before using them to form PUFs. Water content as determined by Carl-Fischer method was below $0.1 \%$.

\begin{tabular}{|c|c|c|c|c|c|c|}
\hline \multirow[b]{2}{*}{ No } & \multirow{2}{*}{$\begin{array}{l}\text { Initial molar ratio } \\
\text { BA:GL:EC:PC }\end{array}$} & \multirow{2}{*}{$\begin{array}{c}\text { Final molar ratio } \\
\text { BA:GL:EC:PC } \\
\text { (from mass loss) }\end{array}$} & \multirow[b]{2}{*}{ Catalyst } & \multirow{2}{*}{$\begin{array}{l}\text { Amount of catalyst } \\
{[\mathrm{mol} / \mathrm{mol} \mathrm{BA}]}\end{array}$} & \multicolumn{2}{|c|}{ Reaction condition } \\
\hline & & & & & $\begin{array}{c}\text { Temperature } \\
{\left[{ }^{\circ} \mathrm{C}\right]}\end{array}$ & $\begin{array}{l}\text { Time of } \\
\text { reaction }[\mathrm{h}]\end{array}$ \\
\hline 1 & 2 & 3 & 4 & 5 & 6 & 7 \\
\hline 1. & 1:4:0:0: & 1:4:0:0 & - & - & 130 & 3 \\
\hline 2. & $1: 4: 8: 0$ & $1: 4: 8: 0$ & $\mathrm{~K}_{2} \mathrm{CO}_{3}$ & 0.075 & $150-160$ & 32 \\
\hline 3 & $1: 4: 12: 0$ & $1: 4: 12: 0$ & $\mathrm{~K}_{2} \mathrm{CO}_{3}$ & 0.088 & $140-150$ & 36 \\
\hline 4. & $1: 4: 0: 8$ & $1: 4: 0: 7$ & $\mathrm{~K}_{2} \mathrm{CO}_{3}$ & 0.100 & 165 & 46 \\
\hline 5. & $1: 4: 0: 12$ & $1: 4: 0: 11$ & $\mathrm{~K}_{2} \mathrm{CO}_{3}$ & 0.088 & $165-175$ & 37.5 \\
\hline 6. & $1: 4: 4: 4^{*}$ & 1:4:4:3 & $\mathrm{K}_{2} \mathrm{CO}_{3}$ & 0.110 & $165-170$ & 19 \\
\hline \multirow{2}{*}{7.} & \multirow{2}{*}{$1: 4: 6: 4^{* *}$} & \multirow{2}{*}{$1: 4: 6: 4$} & \multirow{2}{*}{$\mathrm{K}_{2} \mathrm{CO}_{3}$} & \multirow{2}{*}{0.063} & EC: 150 & 30 \\
\hline & & & & & PC: 160 & 43.5 \\
\hline
\end{tabular}

In column 3 the $B A: G L: E C: P C$ ratio denotes the number of oxyalkylene groups formed upon ring opening of $G L, E C$, and $P C$

* The mixture of $E C$ and $P C$ was used

** PC was added after completion of reaction with EC. 


\section{Foam Preparation}

Foaming tests were conducted on laboratory scale in $250 \mathrm{~cm}^{3}$ paper cups at room temperature. In details oligoetherol (10 g) was mixed with 1.56-2.34 wt $\%$ of Silicone 5340 (pure, Houdry Hülls, USA) as surfactant, the triethylamine catalyst (0.54-3.23 wt\%) and water (2 wt $\%$ ) with respect to oligoetherols. A calculated portion of diphenylmethane 4,4'-diisocyanate (MDI, pure, Merck, Darmstadt, Germany; containing 30\% of trifunctional isocyanates) was then added and the mixture was vigorously stirred until the contents were creamed. Test samples were cut out from the foams thus obtained.

\section{Preliminary studies of foam}

The following properties of foam were studied: apparent density ${ }^{\mathbf{2 0}}$, water uptake ${ }^{\mathbf{2 1}}$, linear shrinkage estimated on the basis of the change of linear dimension of the sample heated for 4 hours at $100^{\circ} \mathrm{C}^{22}$, thermal stability as the weight loss at 150,175 and $200^{\circ} \mathrm{C}$ within one month and compression strength ${ }^{\mathbf{2 3}}$.

\section{RESULTS AND DISCUSSION}

\section{Synthesis and properties of oligoetherols}

Oligoetherols with pyrimidine ring were obtained by hydroxyalkylation of BA with GL at 1:4 molar ratio and further with variable amount of $\mathrm{EC}$ and/or PC.The reaction of BA with GL was performed at $130^{\circ} \mathrm{C}$ for 3 hours. The resin semi-solid product was then dissolved in alkylene carbonate and heated at $150-175^{\circ} \mathrm{C}$ in presence of potassium carbonate catalyst (Table1). The progress of reaction and structure of obtained polyetherols was discussed as before ${ }^{\mathbf{1 0}}$. The composition of obtained oligoetherols (I) was confirmed by elemental analysis and $\mathrm{HN}$ and both corroborated well with calculated ones (Table 2). The obtained oligoetherols showed $\mathrm{AN}=0$ except the semi-product obtained from BA and GL.

The following physical properties of oligoetherols: density, viscosity, and surface tension were studied. The obtained results are collected in Table 3 as temperature dependent parameters within $20-80^{\circ} \mathrm{C}$ range of temperature corresponding to given formulas.

It has been found that all temperature dependencies of studied parameters are typical. In specific density and surface tension of oligoetherols decraease with elongation of oxyalkylene chain. Generally the lower density and surface tension have the oligoetherols containing oxypropylene chains in comparison with those containing oxyethylene chains of comparable length. This can be attributed to the presence of bulky methyl groups in oxypropylene chains resulting in lower space packing of chains. The viscosity and density of oligoetherols measured at $20^{\circ} \mathrm{C}$ are typical for oligoetherols used for formation of PU foams, which were obtained from them (vide infra).

\section{Formation of polyurethane foams}

The oligoetherols obtained from BA, GL and alkylene carbonates were used for obtaining PU foams. The influence of amount of catalyst, isocyanate, water as foaming agent and length of oligoetherol chain on foaming were studied. It has been found that $2 \%$ of water in relation to mass of oligoetherol was the optimized amount. When less water is used the high apparent density foams are formed. On the other hand 3\% water leads to fragile foams. The amount of catalyst (triethylamine) was optimized depending on the reacting system. It has been noticed that too low amount of catalyst results in formation of undercrosslinked foams, with viscous surface. Similar feature was observed in case of the use of excess or deficit amount of isocyanate (see Table 4, compare entries 8 and 20). The amount of catalyst depends on kind of oligoetherol used. In case of PC more catalyst must be used due to presence of less reactive secondary hydroxyl groups (Table 4, compare entries 6 and 13 with 17 and 21). Isocyanate index was 125 for most of foamed compositions except that obtained from oligoetherol synthesized from BA: GL : EC : PC = 1:4:0:12 system, where it was 140 . Cream time were within 20-213 s,

Table 2. Elemental analytical results of products of hydroxyalkylation of BA

\begin{tabular}{|c|c|c|c|c|c|c|c|c|c|c|}
\hline \multirow{3}{*}{ No } & \multirow{3}{*}{$\begin{array}{l}\text { Molar ratio } \\
\text { BA: } \mathrm{GL}: \mathrm{EC}: \mathrm{PC} \\
\text { in product }\end{array}$} & \multicolumn{6}{|c|}{ Elemental analysis [mass \%] } & \multirow{3}{*}{$\begin{array}{c}\text { AN } \\
\mathrm{mg}[\mathrm{KOH} / \mathrm{g}]\end{array}$} & \multirow{2}{*}{\multicolumn{2}{|c|}{$\left[\begin{array}{c}\mathrm{HN} \\
{[\mathrm{mg} \mathrm{KOH} / \mathrm{g}]}\end{array}\right.$}} \\
\hline & & \multicolumn{3}{|c|}{ calculated } & \multicolumn{3}{|c|}{ found } & & & \\
\hline & & $\mathrm{N}$ & C & $\mathrm{H}$ & $\mathrm{N}$ & C & $\mathrm{H}$ & & calc. & found \\
\hline 1. & $1: 4: 0: 0$ & 6.60 & 45.28 & 6.60 & 6.80 & 45.12 & 6.72 & 19.1 & 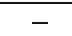 & \\
\hline 2. & $1: 4: 8: 0$ & 3.60 & 49.48 & 7.73 & 3.58 & 49.79 & 8.03 & 0.0 & 578 & 558 \\
\hline 3. & $1: 4: 12: 0$ & 2.94 & 50.42 & 9.98 & 2.99 & 50.55 & 9.56 & 0.0 & 471 & 463 \\
\hline 4. & $1: 4: 0: 7$ & 3.37 & 53.49 & 8.43 & 3.51 & 53.41 & 8.46 & 0.0 & 540 & 527 \\
\hline 5. & $1: 4: 0: 11$ & 2.64 & 55.37 & 8.85 & 2.94 & 55.55 & 9.14 & 0.0 & 423 & 411 \\
\hline 6. & $1: 4: 4: 3$ & 3.62 & 54.16 & 8.01 & 3.65 & 54.00 & 8.54 & 0.0 & 580 & 562 \\
\hline 7. & $1: 4: 6: 4$ & 3.04 & 52.17 & 8.26 & 3.09 & 52.57 & 8.49 & 0.0 & 488 & 467 \\
\hline
\end{tabular}

Table 3. Relationships and values of parameters describing physical properties of oligoethe-rols obtained from BA, GL and alkylene carbonates within $20-80^{\circ} \mathrm{C}$ temperature $(\mathrm{t})$

\begin{tabular}{|c|c|c|c|c|c|c|}
\hline \multirow{3}{*}{$\begin{array}{l}\text { Molar ratio } \\
\text { BA: GL : EC : PC in product }\end{array}$} & \multicolumn{2}{|c|}{ Density (d ) $\left[\mathrm{g} / \mathrm{cm}^{3}\right]$} & \multicolumn{2}{|c|}{ Surface tension $(\mathrm{T})[\mathrm{N} / \mathrm{m}] \cdot 10^{3}$} & \multicolumn{2}{|c|}{ Viscosity $(\eta) \quad[\mathrm{mPa} \mathrm{s}]$} \\
\hline & \multicolumn{2}{|c|}{$d=a t+b$} & \multicolumn{2}{|c|}{$\mathrm{T}=\mathrm{at}+\mathrm{b}$} & \multicolumn{2}{|c|}{$\eta=A t^{-a}$} \\
\hline & a & $b$ & $a$ & $b$ & $A$ & a \\
\hline $1: 4: 8: 0$ & -0.0007 & 1.2721 & -0.091 & 48.31 & $2 \cdot 10^{6}$ & 3.321 \\
\hline $1: 4: 12: 0$ & -0.0007 & 1.2425 & -0.1221 & 39.81 & 433215 & 3.104 \\
\hline $1: 4: 0: 7$ & -0.0007 & 1.1828 & -0.1766 & 49.00 & $5 \cdot 10^{6}$ & 3.661 \\
\hline $1: 4: 0: 11$ & -0.0008 & 1.1356 & -0.1694 & 43.00 & 87029 & 3.134 \\
\hline $1: 4: 4: 3$ & -0.0007 & 1.2328 & -0.0702 & 43.57 & $4 \cdot 10^{6}$ & 3.590 \\
\hline
\end{tabular}


Table 4. The influence of composition on foaming process

\begin{tabular}{|c|c|c|c|c|c|c|c|c|c|}
\hline \multirow{2}{*}{$\begin{array}{l}\text { Molar ratio } \\
\text { BA:GL:EC:PC } \\
\text { in product }\end{array}$} & \multirow{2}{*}{$\begin{array}{l}\text { Com. } \\
\text { No }\end{array}$} & \multicolumn{3}{|c|}{$\begin{array}{c}\text { Composition } \\
{[\mathrm{g} / 100 \mathrm{~g} \text { of oligoetherols] }}\end{array}$} & \multirow{2}{*}{$\begin{array}{l}\text { Isocyanate } \\
\text { index }\end{array}$} & \multicolumn{3}{|c|}{ Foaming process* } & \multirow{2}{*}{$\begin{array}{l}\text { Characteristics of foam } \\
\text { immediately after formation }\end{array}$} \\
\hline & & $\begin{array}{l}\text { isocy- } \\
\text { anate }\end{array}$ & silicon & $\begin{array}{l}\text { cata- } \\
\text { lyst }\end{array}$ & & $\begin{array}{l}\text { cream } \\
\text { time }[\mathrm{s}]\end{array}$ & $\begin{array}{l}\text { rise time } \\
{[\mathrm{s}]}\end{array}$ & $\begin{array}{c}\text { tack free } \\
\text { time }[\mathrm{s}]\end{array}$ & \\
\hline \multirow{7}{*}{$1: 4: 8: 0$} & 1. & 184 & 1.56 & 2.69 & 125 & - & - & - & $S$ \\
\hline & 2. & 184 & 1.56 & 3.77 & 125 & 95 & 5 & 5 & $\begin{array}{l}\text { Fragile; partial } \mathrm{CO}_{2} \text { release during } \\
\text { foaming }\end{array}$ \\
\hline & 3. & 184 & 1.56 & 2.16 & 125 & 47 & 10 & 60 & $\mathrm{R}, \mathrm{RP}, \mathrm{LP}$ \\
\hline & 4. & 184 & 2.34 & 1.08 & 125 & 115 & 60 & 120 & $R, R P$, \\
\hline & 5. & 184 & 2.34 & 0.54 & 125 & 213 & 234 & 265 & R, LFD \\
\hline & $6^{*}$. & 184 & 2.34 & 1.62 & 125 & 132 & 145 & 225 & $\mathrm{R}, \mathrm{RP}$ \\
\hline & 7. & 184 & 2.34 & 3.23 & 125 & 50 & 55 & 80 & SR, RP \\
\hline \multirow{6}{*}{$1: 4: 12: 0$} & 8. & 168 & 1.56 & 1.08 & 125 & 80 & 110 & - & $\mathrm{U}, \mathrm{LFD}$ \\
\hline & 9. & 168 & 1.56 & 2.16 & 125 & 45 & 25 & 30 & $\mathrm{RP}$ \\
\hline & 10. & 168 & 2.34 & 2.16 & 125 & 35 & 25 & 30 & SR, RP \\
\hline & 11. & 156 & 2.34 & 1.62 & 125 & 35 & 15 & 15 & $\mathrm{R}, \mathrm{RP}$ \\
\hline & 12. & 172 & 2.34 & 2.16 & 140 & 40 & 35 & 15 & $\mathrm{R}, \mathrm{RP}$ \\
\hline & $13^{*}$ & 156 & 2.34 & 1.62 & 125 & 30 & 20 & 45 & R RP \\
\hline \multirow{2}{*}{$1: 4: 0: 7$} & 14. & 164 & 1.56 & 2.16 & 130 & 32 & 50 & 5 & $\mathrm{R}, \mathrm{RP}$ \\
\hline & $15^{*}$ & 164 & 1.95 & 1.62 & 130 & 50 & 75 & 23 & $\mathrm{R}, \mathrm{RP}$ \\
\hline \multirow{2}{*}{$1: 4: 0: 12$} & 16. & 152 & 1.56 & 3.23 & 140 & 20 & 30 & 5 & $\mathrm{R}, \mathrm{RP}$ \\
\hline & $17^{*}$ & 152 & 1.56 & 2.16 & 140 & 20 & 30 & 5 & $\mathrm{R}, \mathrm{RP}$ \\
\hline \multirow{5}{*}{$1: 4: 4: 4$} & 18 & 176 & 1.56 & 2.16 & 125 & 37 & 33 & 72 & SR, RP \\
\hline & 19. & 176 & 1.56 & 2.69 & 125 & 46 & 35 & 70 & SR, RP \\
\hline & 20. & 192 & 1.56 & 2.16 & 135 & 57 & 40 & - & U, LP \\
\hline & $21^{*}$ & 176 & 2.34 & 2.16 & 125 & 45 & 36 & 65 & $R, R P$ \\
\hline & 22. & 176 & 1.95 & 2.42 & 125 & 41 & 31 & 50 & $\mathrm{R}, \mathrm{RP}$ \\
\hline \multirow{5}{*}{$1: 4: 6: 4$} & 23. & 128 & 1.56 & 2.69 & 100 & 33 & 15 & 5 & $\mathrm{R}, \mathrm{LP}$ \\
\hline & 24. & 128 & 1.56 & 1.62 & 100 & 36 & 18 & 10 & SR, LFD \\
\hline & 25. & 128 & 1.95 & 1.89 & 100 & 29 & 15 & 10 & $\mathrm{SR}, \mathrm{RP}$ \\
\hline & 26. & 160 & 2.34 & 1.89 & 125 & 51 & 40 & 10 & $R, R P$ \\
\hline & $27^{*}$ & 160 & 1.95 & 1.89 & 125 & 35 & 25 & 10 & $\mathrm{R}, \mathrm{RP}$ \\
\hline
\end{tabular}

$2 \%$ water related to mass of oligoetherol was used

* Cream time: the time elapsed from the moment of mixing to the start of volume expansion;

Rise time: the time from the start of expansion to the moment of reaching the sample final volume;

Tack free time: the time from reaching by the sample its final volume to the moment of loosing its surface adhesion: SR - semigrid foams,

$\mathrm{R}$ - rigid foam, $\mathrm{U}$ - undercrosslinked foam, LFD - low foaming degree, RP - regular pores, LP - large pores.

while rise time was within 5-234 s. They depend mostly on amount of isocyanate and catalyst applied. Increasing amount of catalyst and decreasing amount of isocyanate remarkably shortened those times (Table 4 , compare 3,4 , and 5; 19 and 20, as well as 24 and 25). Tack free time was within 5-65 s. Tack free time was the longest (almost 4 minutes) in case of foam obtained from oligoetherol synthesized from BA: GL:EC $=1: 4: 8$.

Optimized foams were subjected to physical properties determination. It has been found that all foams were rigid. Their apparent density was within $48-92 \mathrm{~kg} / \mathrm{m}^{3}$. Water uptake after 24 hours was $6-22 \%$. Lower water uptake showed the foams obtained from oligoetherols containing oxypropylene groups, presumably due to their hydrophobic character. Generally the foams obtained here show low linear shrinkage, not exceeding couple of percent (Table 5). Linear dimensions after thermal exposition at $150^{\circ} \mathrm{C}$ for 20 days are no higher than $8 \%$ and do not change after next 20 days. The foams obtained from oligoetherols containing oxypropylene units indicated lower shrinkage than those containing oxyethylene mers. The studies on thermal stability of obtained foams were conducted by dynamic methods (TG, DTG, Fig. 1). They showed that $5 \%$ mass loss of the foams occur at $200-250^{\circ} \mathrm{C}$, while $50 \%$ mass loss at $330-375^{\circ} \mathrm{C}$ (Table 6). The thermal stability studied by static method were conducted at 150,175 , and $200^{\circ} \mathrm{C}$ within one month. The continuous mass loss was observed within one month, however it was the biggest within first day of heating

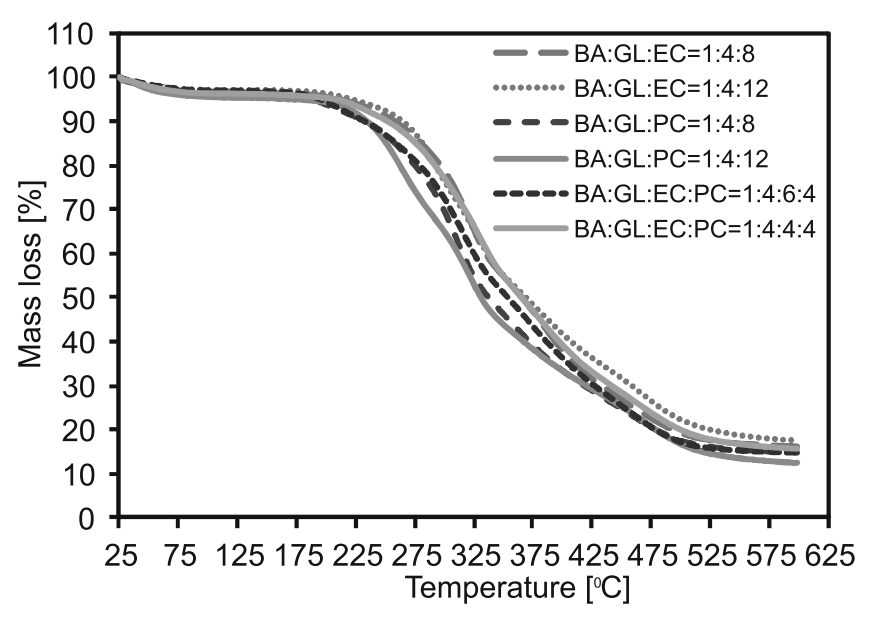

Figure 1. Mass loss of PU foams vs temperature measured by thermogravimetrically (the initial molar ratio of reagents BA:GL:EC:PC are given in inset)

(Fig. 2). The highest thermal stability measured as the lowest mass loss was observed for the foam formed from oligoetherol synthesized in BA:GL:EC:PC $=1: 4: 6: 4$ molar ratio system, i.e. containing both oxyethylene and oxypropylene units. The oligoetherol used had terminal oxypropylene units, i.e. secondary hydroxyl groups. The mass loss of that foam was $12 \%$ at $150^{\circ} \mathrm{C}$ and reached $38.5 \%$ at $200^{\circ} \mathrm{C}$, with concomitant remarkable increase of compressive strength in comparison with foam not thermally treated. Our examination of commercial PUF (obtained from sorbitol, and ethylene or propylene oxides) 
Table 5. Some properties of obtained foams

\begin{tabular}{|c|c|c|c|c|c|c|c|c|c|}
\hline \multirow{3}{*}{$\begin{array}{l}\text { Comp. } \\
\text { No as in } \\
\text { Table } 4\end{array}$} & \multirow{3}{*}{$\begin{array}{c}\text { Molar ratio } \\
\text { BA:GL:EC: } \\
\text { PC in product }\end{array}$} & \multirow{3}{*}{$\begin{array}{l}\text { Density } \\
{\left[\mathrm{kg} / \mathrm{m}^{3}\right]}\end{array}$} & \multirow{3}{*}{$\begin{array}{c}\text { Absorb. of } \\
\text { water } \\
\text { [wt \%] after } \\
24 \mathrm{~h}\end{array}$} & \multicolumn{6}{|c|}{ Dimensional Stability [\%] in temperature $150^{\circ} \mathrm{C}$} \\
\hline & & & & \multicolumn{3}{|c|}{ after $20 \mathrm{~h}$} & \multicolumn{3}{|c|}{ after $40 \mathrm{~h}$} \\
\hline & & & & $\begin{array}{l}\text { Legth } \\
\text { change }\end{array}$ & $\begin{array}{l}\text { Broadness } \\
\text { change }\end{array}$ & $\begin{array}{l}\text { Thickness } \\
\text { change }\end{array}$ & $\begin{array}{l}\text { Legth } \\
\text { change }\end{array}$ & $\begin{array}{l}\text { Broadness } \\
\text { change }\end{array}$ & $\begin{array}{c}\text { Thickness } \\
\text { change }\end{array}$ \\
\hline 6. & $1: 4: 8: 0$ & 91.6 & 21.79 & 2.9 & 7.7 & 0.0 & 2.9 & 7.7 & 0.0 \\
\hline 13. & $1: 4: 12: 0$ & 71.4 & 7.30 & 4.6 & 3.1 & 14.2 & 5.8 & 5.8 & 14.2 \\
\hline 15. & $1: 4: 0: 7$ & 56.1 & 15.75 & 3.5 & 4.0 & 4.5 & 3.5 & 4.0 & 4.5 \\
\hline 17. & $1: 4: 0: 12$ & 48.1 & 6.33 & 2.9 & 2.7 & 3.1 & 2.9 & 2.7 & 3.1 \\
\hline 21. & $1: 4: 4: 4$ & 73.1 & 23.90 & 0.0 & 0.0 & 6.7 & 0.0 & 0.0 & 6.7 \\
\hline 27. & $1: 4: 6: 4$ & 66.1 & 11.27 & 2.3 & 7.1 & 8.3 & 3.5 & 8.9 & 8.3 \\
\hline \multicolumn{2}{|c|}{ HMBA:PO $=1: 12-1: 18$} & $44.6-48.4$ & $7.83-9.07$ & $2.1-14.6$ & & & & & \\
\hline \multicolumn{2}{|c|}{$\mathrm{AU}: \mathrm{EO}=1: 7.8$} & $51.0-73.5$ & $15.3-32.5$ & $\begin{array}{c}(-8.4)- \\
(-2.2)\end{array}$ & $(-8.5-(-0.2)$ & $(-8.4)-1.8$ & $\begin{array}{c}(-11.6)- \\
(-2.2)\end{array}$ & $\begin{array}{c}(-13.5)- \\
(-0.8)\end{array}$ & $\begin{array}{c}(-9.6)- \\
(-1.3)\end{array}$ \\
\hline \multicolumn{2}{|c|}{$\mathrm{AU}: \mathrm{EO}=1: 12$} & $44.4-55.3$ & $11.3-15.4$ & $\begin{array}{l}(-5.3) \\
(-2.1)\end{array}$ & $(-7.4-(-2.2)$ & $(-6.8)-2.0$ & $\begin{array}{c}(-7.2)- \\
(-2.4)\end{array}$ & $\begin{array}{c}(-8.6)- \\
(-2.7)\end{array}$ & $\begin{array}{c}(-7.5)- \\
(-4.1)\end{array}$ \\
\hline \multicolumn{2}{|c|}{$\mathrm{AU}: \mathrm{PO}=1: 7.4$} & $45.9-53.9$ & $5.8-6.2$ & $\begin{array}{l}(-4.4) \\
-0.7\end{array}$ & $(-2.8)-0.7$ & $(-1.5)-0.0$ & $(-4.4)-0.6$ & $(-2.8)-0.7$ & $\begin{array}{c}(-1.7)- \\
(-0.6)\end{array}$ \\
\hline \multicolumn{2}{|c|}{$A U: P O=1: 116$} & $42.1-50.9$ & $8.3-10.4$ & $5.7-8.7$ & $8.7-12.1$ & $0.0-14.0$ & $3.5-7.1$ & $9.1-11.9$ & $(-3.3)-12.9$ \\
\hline
\end{tabular}

HMBA - hydroxymetyl derivative of BA;

* HMBA : PO molar ratio used in synthesis of oligoetherols ${ }^{13}$;

$\mathrm{AU}$-6-aminouracil;

$\mathrm{AU}: \mathrm{EO}$ and $\mathrm{AU}: \mathrm{PO}$ molar ratio of 6-aminouracil to ethylene or propylene oxides, respectively, used in synthesis of oligoetherols ${ }^{15}$.

Table 6. Thermostability and compressive strength of foams

\begin{tabular}{|c|c|c|c|c|c|c|c|}
\hline \multirow{3}{*}{ Comp. No as in Table 4} & \multirow{2}{*}{\multicolumn{3}{|c|}{$\begin{array}{l}\text { Mass loss in \% wt. after exposition in } \\
\text { month in temperature }\end{array}$}} & \multicolumn{4}{|c|}{ Compressive strength [MPa] } \\
\hline & & & & \multirow{2}{*}{$\begin{array}{l}\text { before } \\
\text { exposition }\end{array}$} & \multicolumn{3}{|c|}{ after exposition in temperature } \\
\hline & $150^{\circ} \mathrm{C}$ & $175^{\circ} \mathrm{C}$ & $200^{\circ} \mathrm{C}$ & & $150^{\circ} \mathrm{C}$ & $175^{\circ} \mathrm{C}$ & $200^{\circ} \mathrm{C}$ \\
\hline 6. & 12.46 & 26.05 & 39.83 & 0.568 & 0.531 & 0.391 & 0.296 \\
\hline 13. & 12.35 & 31.85 & 43.59 & 0.164 & 0.197 & 0.312 & 0.345 \\
\hline 15. & 11.98 & 27.14 & 40.72 & 0.184 & 0.288 & 0.213 & 0.329 \\
\hline 17. & 13.09 & 30.21 & 39.87 & 0.268 & 0.819 & 0.407 & 0.356 \\
\hline 21. & 14.30 & 27.03 & 43.91 & 0.304 & 0.329 & 0.267 & 0.179 \\
\hline 27. & 12.00 & 27.24 & 38.54 & 0.108 & 0.255 & 0.272 & 0.916 \\
\hline HMBA:PO = 1:12-1:18 & $29.1-36.5$ & $40.3-45.1$ & $47.4-51.2$ & $0.105-0.175$ & $0.140-0.238$ & $0.129-0.257$ & $0.104-0.236$ \\
\hline $\mathrm{AU}: \mathrm{EO}=1: 7.8$ & $23-25$ & $32-34$ & $38-42$ & $0.05-0.18$ & $0.24-0.51$ & $0.32-0.67$ & $0.66-1.78$ \\
\hline $\mathrm{AU}: \mathrm{EO}=1: 12$ & $18-28$ & $32-37$ & $42-48$ & $0.11-0.18$ & $0.23-0.41$ & $0.37-0.57$ & $0.35-0.67$ \\
\hline $\mathrm{AU}: \mathrm{PO}=1: 7.4$ & $12-16$ & $24-29$ & $37-41$ & $0.15-0.24$ & $0.22-0.32$ & $0.23-0.28$ & $0.28-0.33$ \\
\hline $\mathrm{AU}: \mathrm{PO}=1: 11.6$ & $25-27$ & $35-38$ & 45 & 0.19 & - & 0.14 & - \\
\hline
\end{tabular}

showed lower thermal resistance; after 1 day exposition at $150^{\circ} \mathrm{C}$ the mass loss was $21.4 \%$, while it increased to $37.4 \%$ after thermal exposure at $200^{\circ} \mathrm{C}$. Generally the obtained our foams from BA showed 0.108-0.304 MPa compressive strength i.e. higher than that described in ${ }^{\mathbf{1 3}, 15}$. The exception was the foam obtained from BA:GL:EC = 1:4:8 system, which indicated higher value (0.568 MPa). It should be mention that the studied foams revealed increase of compressive strength after thermal exposure (Table 6), except the latter one. The exceptionally high increase of compressive strength demonstrated the foam obtained from BA:GL:EC:PC = 1:4:6:4 system, which was as high as $750 \%$ after one month exposure at $200^{\circ} \mathrm{C}$. However generally the obtained foams showed increase of compression strength after exposition at $150^{\circ} \mathrm{C}$, but decrease after further exposition at $200^{\circ} \mathrm{C}$, still being higher in comparison with non-treated thermally. Heat conductance coefficient of foams obtained here was $0.038-0.056 \mathrm{~W} / \mathrm{m} \mathrm{K}$ so it was higher than that of typical PU foams $(0.019-0.026)^{19}$. The properties of obtained here foams was compared with those obtained from oligoetherols synthesized from hydroxymethyl derivative of barbituric acid (HMBA) and propylene oxide (PO) ${ }^{\mathbf{1 3}}$ and those synthesized from 6-aminouracil and oxiranes (Tables $5,6)^{\mathbf{1 5}}$. The foams described in this paper have lower linear shrinkage, while they have similar water uptake and higher apparent density if compare with mentioned ones. However, their thermal stability measured by mass loss is definitely higher than that obtained from oligoetherols based on hydroxymethyl derivatives of BA and oxiranes. They also show considerably higher thermal stability at $150^{\circ} \mathrm{C}$ and was slightly higher at $175^{\circ} \mathrm{C}$ if compare with those obtained from oligoetherols synthesized from 6-aminouracil and oxiranes. The thermal stability of all foams at $200^{\circ} \mathrm{C}$ is similar. Also they possess higher compressive strength both before and after thermal exposure than the foams described in our paper ${ }^{13}$. One can see that foams described here reveal higher compression strength both before and after thermal exposure at 150 and $175^{\circ} \mathrm{C}$ than those obtained from 6-aminouracil ${ }^{15}$. Presumably their improved thermal resistance and mechanical strength are related to higher functionality of oligoetherols used, for which the suitable substrate was glycidol. The high functionality of obtained oligoetherols resulted in increased degree of crosslinking of the PU foams obtained. At $200^{\circ} \mathrm{C}$ the decomposition processes prevails in all foams; consequently both mass loss and mechanical properties become similar respectful the oligoetherol used. 


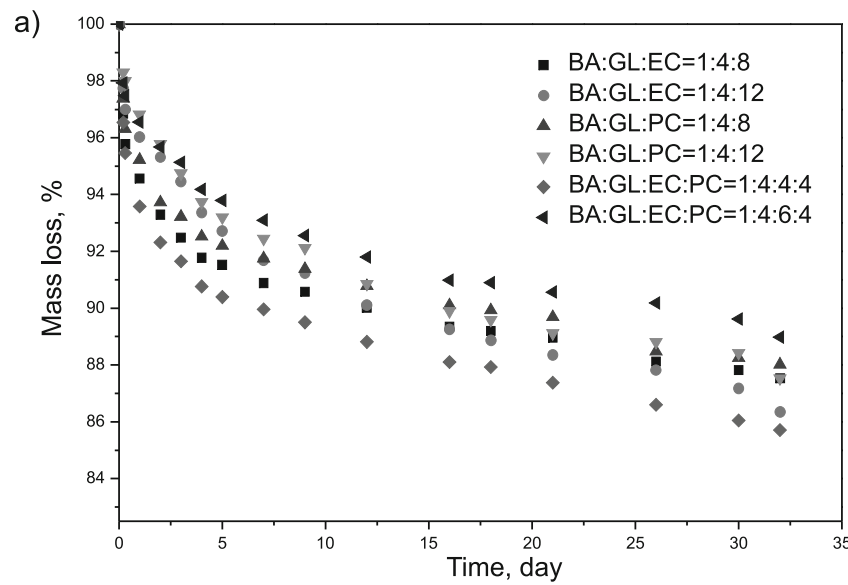

b)

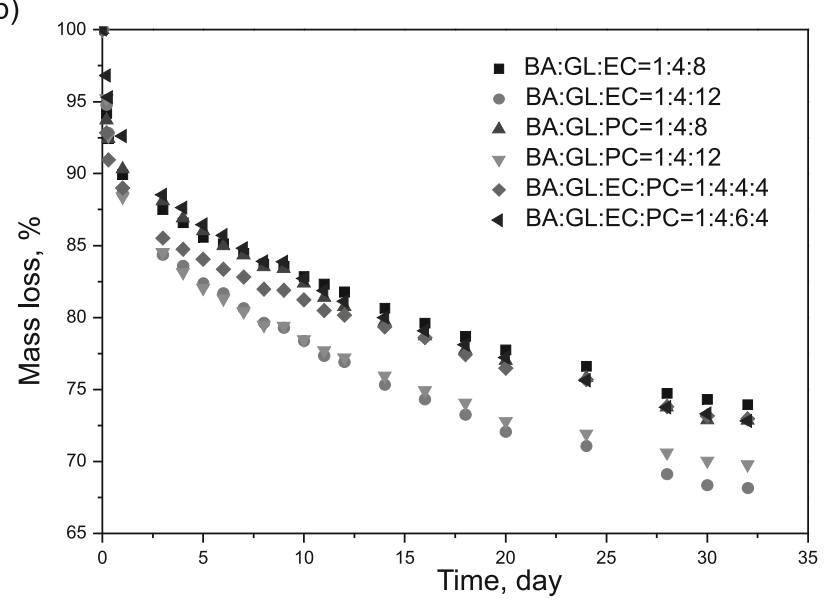

c)

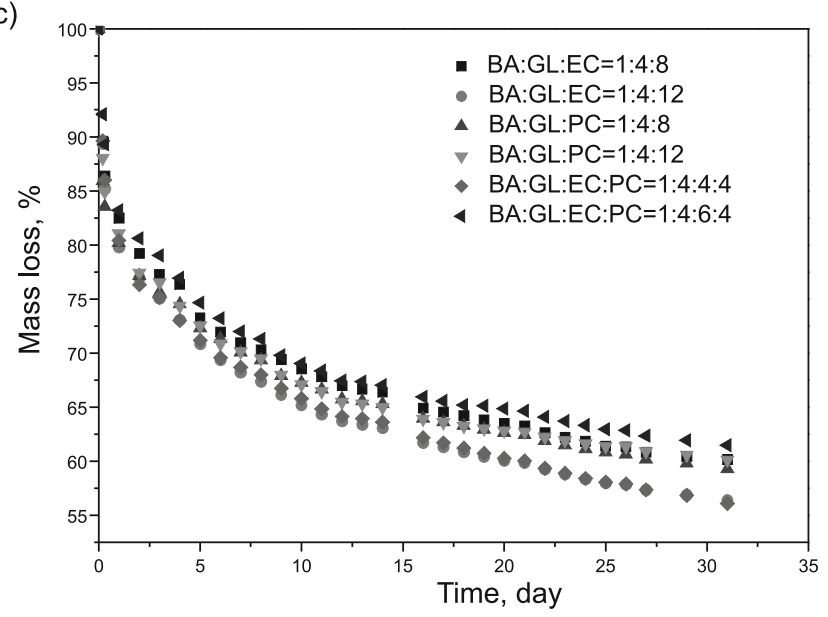

Figure 2. Thermal stability of foams measured as mass loss after one-month exposure to temperature a) $150^{\circ} \mathrm{C}$, b) $175^{\circ} \mathrm{C}$, c) $200^{\circ} \mathrm{C}$ (the initial molar ratio of reagents $\mathrm{BA}: \mathrm{GL}: \mathrm{EC}: \mathrm{PC}$ are given in inset)

\section{CONCLUSIONS}

The oligoetherols obtained from consecutive reactions of barbituric acid with glycidol and further with alkylene carbonates can be used to obtain rigid polyurethane foams containing pyrimidine ring. The proposed method of synthesis of oligoetherols is straightforward, does not require solvents, which makes them ecologically reasonable.

The polyurethane foams have similar physical properties as the classic ones except their enhanced thermal resistance. They stand long-time heating even at $200^{\circ} \mathrm{C}$. Moreover thermal exposition of foams generally results in increase of their compressive strength in comparison with not exposed foams.

\section{LITERATURE CITED}

1. Frisch, K., Tummers, D. \& Nijehuis, A. (1980). U.S. Patent No. 4198,505.

2. Śnieżek, T., Andrysiak, E., Montewski, W., Gniadowski, H. \& Wojciechowski, J. (1973). PL Patent No. 69,168.

3. Kijowska, D. \& Kucharski, M. (2004). Polyetherols from melamine and alkylene carbonates. Properties and application of foamed polyurethanes. J. Appl. Polym. Sci. 94, 2302-2308. http://dx.doi.org/10.1002/app.21165

4. Lubczak, J. (2007). Polyurethane foams with purine rings. Polimery 52(7-8), 595-600.

5. Lubczak, R. (2010). Linear Oligoetherols and Polyurethanes with Carbazole Ring. J. Appl. Polym. Sci. 117, 16-23. http:// dx.doi.org/10.1002/app.31088

6. Lubczak, R. (2012). Trifuntional oligoetherols and polyurethane foams with carbazole ring. Open J. Organic Polym. Mat. 2, 1-6. http://dx.doi.org/10.4236/ojopm.2012.21001

7. Lubczak, R. (2012). Oligoetherols and polyurethane foams with carbazole ring, e-Poly-mers 070, 1-3.

8. Lubczak, J. (2003). Hydroxyalkylation of nitrogen-containing heterocyclic compounds. Curr. Tren. Polym. Sci. 8, 73-105. http://dx.doi.org/10.1002/chin.200601254.

9. Lubczak, J. \& Mendyk, E. (2008). Stable enol form of barbituric acid. Heterocycl. Comm. 14(3), 149-154. http://dx.doi. org/10.1515/HC.2008.14.3.149

10. Kania, E. \& Lubczak, J. Oligoetherols with pyrimidine ring, Polymers (in press).

11. Kosterna, J. \& Lubczak, J. (2009). Acrylic monomers and polymers with pyrimidine ring. Polimery 54(7-8), 581-584.

12. Ślączka, A. \& Lubczak, J. (2008). Urethane oligomers with pyrimidine rings. Polimery 53(10), 760-763.

13. Ślączka, A. \& Lubczak, J. (2007). Hydroxyalkylation of barbituric acid. Part II. Synthesis of polyetherols with pyrimidine ring. J. Appl. Polym. Sci. 106, 4067-4074.

14. Chmiel-Szukiewicz, E. (2007). Polyetherols obtained from 6-aminouracil and oxiranes. J. Appl. Polym. Sci. 103, 1466-1472. http://dx.doi.org/10.1002/app.25100

15. Chmiel-Szukiewicz, E. (2008). Polyurethane foams with 1,3-pyrimidine ring. J. Appl. Polym. Sci. 109, 1708-1713. http:// dx.doi.org/10.1002/app.27159

16. Kijowska, D. (2005). Alkylene carbonates with penta-membered ring - obtaining, properties and application., Przem. Chem., 84, 678-683.

17. Brojer, Z., Hertz, Z. \& Penczek, P. (1972). Epoxy Resins. WNT, Poland.

18. Kijowska, D., Wołowiec, S. \& Lubczak, J. (2004). Kinetics and mechanism of initial steps of synthesis of polyetherols from melamine and ethylene carbonate. J. Appl. Polym Sci. 93, 294-300. http://dx.doi.org/10.1002/app.20453

19. Czupryński, B. (2004). Problems on chemistry and technology of polyurethanes. Ed. Wydawnictwo Akademii Bydgoskiej, Poland.

20. Polish Committee for Standardization (2000). Cellular Plastics and Rubbers. Determination of apparent (bulk) Density. Polish (European) Standards PN-EN ISO 845-2000.

21. Polish Committee for Standardization. Cellular Plastics, rigid. Determination of Water Absorption. Polish (European) Standards PN-EN ISO 2896-1986.

22. Polish Committee for Standardization. Cellular Plastics, rigid. Test of dimensional Stability. Polish (European) Standards PN- EN ISO 2796-1986.

23. Polish Committee for Standardization.Cellular Plastics, Compression Test for rigid Materials. Polish (European) Standards PN- EN ISO 844-1978. 